\title{
Fake News From The Islamic Perspective
}

\author{
${ }^{1}$ SITI SURIANI OTHMAN, ${ }^{2}$ FAUZIAH HASSAN, \\ ${ }^{3}$ SAFIYYAH AHMAD SABRI, ${ }^{4}$ LIANA MAT NAYAN \\ 1,2,3 Universiti Sains Islam Malaysia, 71800, Bandar Baru Nilai, Negeri Sembilan, Malaysia, \\ ${ }^{4}$ Universiti Tunku Abdul Rahman, Sungai Long Campus, Kajang, Selangor, Malaysia. \\ correspondence author:: ${ }^{1}$ suriani@usim.edu.my;
}

\begin{abstract}
The facts and truths of the news have always become the imperative point in informing and updating the public. However, the fake news emerged has disrupted the originality and authenticity of the news. It has become a longstanding issue when social media sites become a platform in disseminating fake news, videos, photos, etc. rapidly to the public. They become more aggressive due to the development of information communication technologies and made the quality of the news posted become questioned. Furthermore, fake news emerges abundantly and easily on online platforms than before. Thus, this paper discusses fake news by examining the current trends of fake news in today's journalism through the previous scholarly discussion on this topic. In the era of Revolution Industry 4.0, the role of technology in reducing or/and increasing the threat of fake news in modern communication is also discussed. Lastly, this paper illustrates the concept of Islam towards the issue of fake news and provide what Islam has to say about fake news. It shows that Islam teaches us to be "wasatiyyah" or being moderate to uphold the trustworthy and highlight self-respect by dissemination news with facts, values, and reliability.
\end{abstract}

Keywords: fake news, islamic perspective, online journalism

\section{Introduction}

Fake news is notorious in the digital communication world today although the practice is nothing new to journalism. Today, it is discussed not only by ordinary people but also by communication scholars and invite many studies to understand the phenomenon and to suggest ways to reduce the negative impact of producing and disseminating fake news among the public. It is such an unprecedented phenomenon that fake news now appeared too real, sometimes more than real (Berkowitz and Schwartz, 2015).

Fake news is yet to be defined with a firm definition by scholars. Some terms are used to define fake news such as "intentional deception" (Finneman and Thomas, 2018), information disorder (Claire Wardle quoted in Jorgensen et al. 2018), and "similar to real news" (Tandoc et al., 2018).

The literature on fake news has been summarized by Jorgensen et al. (2018) that includes studies on fake news in the posttruth era in terms of professional practices including the needs of fact-checking using new technology, the relationship between news originations and audience, the changing practice of journalistic labor and the issue of journalistic practices and audience relations. It has also been shown that social media is the main tool that enables the production and spread of fake news in the modern era. However, it is also modern technology that allows fact-checking to be performed more rigorously by journalists to reduce misinformation.

In Islam, producing lies and disseminating lies are both sinful (Jasmi, 2005). According to the study by Wan Hakimin et.al, (2018) they stated that Islam teaches us to check and verify any information that we received before disseminating them with regard to maintain harmony and peace among Muslim societies. This is because any information or news obtained without the 
guarantee of truth and certainty will result in hostility and strife. This applies to all kinds of activities that involve elements of deception including fake news. Hence, the objective of this paper is to discuss fake news from Islamic perspective. Derived from previous scholarly discussions and Islamic manuscripts on fake news, this paper attempts to provide what Islam has to say about fake news. We start the discussion by presenting an overview on fake news in today's journalism, the relationship between fake news and technology, and fake news in Islamic perspective.

\section{Research Methodology}

A Conceptual Research. This is a conceptual paper solely to study the topic on fake news from the Islamic perspective. The study reviews previous literature from journal articles, books, and newspaper clippings as the method to collect the data and analyze the literature. According to Gilson and Goldberg (2015), many of the conceptual papers do not provide data since it only focuses on the integration of findings and perspectives from many published academic sources related to the topic. Thus, the conceptual paper is basically will provide logic and arguments based on the literature reviews rather than testing the data empirically. Snyder (2019) stated that the use of literature reviews is to provide an overview of a certain issue or research problem. Snyder also explained that the researchers can use various methods, strategies, standards, and guidelines developed to analyze the literature review. This concept paper is intended to study and identify what is fake news from Islamic perspective. Other than that, the paper goes to analyze the current scenario of fake news and the technology that has affected the fake news. Several methods were used to collect and analyze the literature. The collection of articles related was gathered through academic databases pertaining to fake news such as Scopus, Science Direct, and Web of Science. On top of that, Google search engine also has been used to search the term of 'fake news'. The most helpful literature was from Tandoc et al. in 2018 which identified six ways (satire, parody, fabrication, manipulation, propaganda, and advertising) to explain the term of fake news based on their review on published academic studies. Hence, from their study, we know that the issues of fake news can be explored in various aspects and not only into media specifically. Thus, this concept paper tries to have a different idea by discussing the fake news from Islamic perspective. On top of that, books, presentation papers, and newspaper clippings play roles to support the information and arguments. The same method applied to find any online books, paper presentations, and news articles related to the topic.

\section{Results and Discussions \\ Fake News in Today's Journalism}

Fake news is used as a term that denounces media and journalism, and simultaneously a term for various levels of wrong and fabricated information. Fake news can be categorized into intentional and unintentional, where unintentional can include sloppy reporting and propaganda respectively (Quandt et al. 2019).

Claire Wardle's keynote speech (Jorgensen et al. 2018) proposes that the notion of fake news can be understood from the broad issue of "information disorder". To her, much information that is considered as fake news is not actually fabricated but is used out of context or being manipulated by journalists. Fake news, she added, ranges from satirical news, which is the least harmful, to fabricated content which is the most harmful to the audience. At the same time, the harm of fake news is not merely about the impact of fake news to the audience but can also be extended to "fake news label" which is the instrument to delegitimize news media.

This includes obvious journalistic deception as described by Lasorsa and Dai (2001). They identified seven types of fake news based on journalistic activities: full fabrication (total fabrication of a news event), fact fabrication (fabrication of particular elements of a story), dateline fabrication (where the reporter was not present at the scene they were identified as being), source fabrication (invention of a source), quote fabrication (falsifying a quote), plagiarism (duplication of another's work) and the use of undisclosed bylines (where work by others is not accurately attributed).

This brings us to some recent definitions of fake news that have been discussed by scholars that include "appropriates the look and feel of real news from how websites look to how articles are written and how photos include attributions." (Tandoc et al. 2018), while Finneman and Thomas (2018) define 
fake news as sharing some concepts with media hoaxing: awareness of falsehood, intent, and scale. Therefore, they concluded that "fake news is the intentional deception of a mass audience by nonmedia actors via a sensational communication that appears credible but is designed to manipulate and is not revealed to be false (p.9).

In journalism, fake news is nothing new. The act of muckraking, for example, historically is the act of faking facts and information. However, today, in the digital era, fake news is much more rampant because it is so easy to produce fake news and easy to share. In this instance, social media is seen to be the main culprit of this phenomenon. Newman et al. (2017) in Reuters Institute Digital News Report 2017 demonstrates growth in social media for news such as WhatsApp. Malaysia, for instance, recorded 51 percent of usage, followed by Brazil of 46 percent and Spain of 32 percent.

The popularity of social media does not only show in consumer use but also in journalism practice. Johnson and Kelling's (2017) study on Facebook demonstrate how Facebook has changed the whole practice of professional journalism. For example, Facebook is seen as a new form of news organization when they can criticize traditional news organizations.

In India, the literature suggests a slightly different phenomenon of scholarly research in fake news. Bhaskaran et al. (2017) for instance argued that while debates on fake news in the West engaged with the non-elite audience and the culture of factchecking, in India, the focus is more on issues on hampering institutional forces and outdated journalism curricula in universities. This suggests for issues related to fake news must be tackled not only from journalistic perspective but also public policies (Tambini, 2017).

A further question arises when discussing fake news in the western democracies. Humprecht (2018) compared online disinformation re-published by factcheckers from the US, the UK, Germany, and Austria. The findings demonstrate that there are significant differences between Englishspeaking and German-speaking countries. For instance, partisan disinformation is mostly shared in the US and the UK, while in Germanspeaking countries, fake news attacks political actors. This study concludes by arguing that online fake news is shaped by a specific national information environment and not a merely technological-related issue.

At the same time, individuals also need to play their role as agents to reduce the impact of fake news. Tandoc et al. (2018) studied 2501 Singaporeans to understand how people authenticate information they receive from social media. The study shows that individuals rely on their own judgment and the source of the message to determine trust. However, if they still doubt the authenticity, they utilize external resources to authenticate the news they read. This further suggests the need for evidence-based journalism to be one of the crucial forms of journalism in the future. The power of such a form of journalism has been proven in the exposure of global scale wrongdoing such as the Panama Papers. It is here we can see how digital technologies, although they are responsible for various uncertainties and misuse of journalism principles, it also offers opportunities for evidence-based journalism to flourish (Carson and Farhall, 2018).

This may further be associated with a larger issue in journalism which is trust. Reuters Institute Digital News Report 2017 also shows that based on YouGov survey of over 70,000 online news consumers in 36 countries including the US and UK, there are variations in trust in over 36 countries in the study. Finland records the highest country who trust the news (62 percent), while Greece and South Korea are the lowest (23 percent) (Newman et al., 2017). Teenagers, in a study conducted by Marchi (2012), shows different attitude toward news and their trust to news. They talk with trusted adults to reconfirm news they read and rely on social networking to get latest news. Although this study reveals that teens value truth in reporting, they unfortunately are not convinced on trustworthiness of professional news. Traditional news is "boring" and "predictable" in terms of subject matters discussed. On the other hand, postings on social media are more opinioned and allow them to understand the wider meanings of political happenings and thus develop their own opinions on issues.

\section{Fake News and Technology}

The majority of scholars relate fake news as similar to disinformation campaigns, cyber propaganda, cognitive hacking, and information warfare, which all can conclude 
as the manipulation of public opinion in order to achieve certain goals (Gu, Kropotov \& Yarochkin, 2017). Later, Lazer, et al. (2017) stated that fake news overlaps with other information disorders, such as misinformation, which can be defined as false or misleading information, and disinformation, which defined as false information that is purposely spread to deceive people. No matter what, the increasing of fake news is due to the connectivity and digital platforms that make it possible to share and spread information, where the barriers of time and distance do not exist anymore, while at the same time, ease the process of spreading fake news that affects our real life. Each of fake news issues proved the influence of this technological manipulation can have on people's daily lives either positively or negatively (Gu, Kropotov \& Yarochkin, 2017).

Historically, the faking of news stories has been around for a long time and has evolved into something far more aggressive due to the development of information communication technologies that allow rapid transmission and communication (Greg, 2018). Unfortunately, every development of new technology, from the telegraph in the 19th century to contemporary social media algorithms, has initiated new possibilities of deception and fabrication (Gelfert, 2018).

Lazer, et al. (2018) defined "fake news" to be invented information that mimics news media content in form but not in organizational process or intent. However, these fake-news channels have lack news media's editorial practices which also affecting the process of ensuring the accuracy and credibility of information. According to Posetti and Matthews (2018), the advancement of technology allowed the fake news channels to copy the real news websites and with less effort, they easily manipulate audio and video to create copied representations of any number of sources.

Fake news has also been used to refer to the manipulation of real images or videos to create a false narrative. Manipulation of images has become an increasingly common occurrence with the advent of digital photos, powerful image manipulation software, and knowledge of techniques. Effects may range from simple to complex, and simple adjustments can include increasing color saturation and removing minor elements (Tandoc Jr., Lim \& Ling, 2018).

The manual editing, publication, and amplification, which were handled by the experts previously, now can be done by anyone due to the technology of Internet. The internet is providing a vast array of services where content can be published, from basic web servers, via hosting services, to social networks where content is connecting developers and consumers. Unlike traditional news processing, there is not a single point where the content of fake news could be supervised, controlled or quality-assured, because people are their own gatekeepers without depending to any professionals (Turk, 2018).

Much of the evidences point a finger at social media sites, and online news distribution sites in general, as the main sources of rising concerns about fake news, false news, and the quality of news (Martens et al. 2018). Platforms like Facebook are in a powerful position to influence the process of spreading fake news. Relatively, both real and fake news can circulate through social media because the technology suits fake and real news equally well (Turk, 2018). Despite the advantages provided by social media, the quality of news on social media is lower than traditional news organizations. However, because providing news online is much cheaper, faster, and easier to disseminate through social media, large volumes of fake news, such as those news articles with intentionally false information, are produced online for a variety of purposes, such as financial and political gain (Shu, Sliva, Wang, Tang \& Liu, 2017).

Mohale and Leung (2019) stated that the extreme spreading of fake news can have serious negative impacts on society because it leads to an inequality of the news nature which is, to tell the truth. Furthermore, propagandists and politicians always use fake news to convey their political messages and manipulate readers to accept certain biased and distorted facts, and these fake news influences on how their readers react to their environments, and frequently generates misunderstandings, doubt and delay the ability to differentiate between what is right and what is not effective.

Other than that, the evolution of smart devices such as mobile phones and other handheld devices has enabled more diverse services to consumers, and with the advancement in mobile technologies, the services are also becoming smarter, ubiquitous, and more pervasive. The current evolution towards $5 \mathrm{G}$ networks is not only 
benefiting the consumers but also the involved stakeholders. This advancement technology will help various stakeholders to enhance their business models for bigger and better revenues (Ahmad et al.,2019). However, Yuval Harari (2018; cited in Bakowicz, 2019), who combines fake news with advertising, claims that false information is often the foundation of business activities, such as Coca-Cola Company, which builds its brand on the combination of carbonated drink with youth, fitness, and joy, while in fact, drinking Coke contributes to the development of diabetes and heart disease.

Nagi (2018) mentioned that social media, messaging apps, and various email platforms provide a constant stream of news to the users either from close people or from total strangers. News stories on social media can now come in the form of links or shares, which is not stressing the original publisher and might allow the altering of the source. Unfortunately, fake news also comes to users, whether they expect it or not. In the end, false news can be brought into the market because it is cheap to produce and distribute. If in a real environment, publishers of fake news would quickly be caught, lose their credibility, and might unable to set up a sustainable business. However, publishers of online fake news which experience low production and zero distribution costs, combined with quite definite access to advertising revenue, make false news production economically more sustainable (Martens et al., 2018). Since the origin of the fake news is hard to trace, it will be much more difficult to locate and take legal action to those behind such actions (Nagi, 2018).

According to Jang et al. (2018), the process of searching for the root of fake news on social media is particularly challenging for numerous reasons. First, it is difficult to track down the original source of online information because it is often posted and published by authors whose identity is hidden or unknown. Second, unlike traditional publication outlets where the citation of sources is the norm, social media dialogues often neglect standard protocols for reporting who says what. Finally, as social media content is often transformed through the process of sharing and spreading, it is hard to determine which version of media content is closest to the original.

No matter what, even if the quest for a system to prevent the creation of fake news contradict with many democratic values like freedom of speech, however, it is possible to identify elements in the technology which can help to solve the issue of fake news. Figueira and Oliveira (2017) believe that, currently, the necessary settings and resources to attack this problem are available, such as the technology in form of algorithms, the hardware to cope with big data, and access to big data for training the algorithms. Besides, various fact-checking organizations, such as Snopes and PolitiFact, have been initiated to expose or confirm news stories. While these organizations are based on "fact-checking journalism", that relies on human verification, more desirable automated technological solutions have been proposed by technological companies like Fact Mata which aim to provide fake news detection solutions to businesses and consumers and assign credibility scores to web content using artificial intelligence. Various other automated solutions in the form of plug-ins and applications such as BS-Detector and Crosscheck provide similar automated fact-checking services (Zubiaga et al. 2016).

In conclusion, technology in general and social media in particular does not only introduce new challenges for dealing with fake news but also offers a potential for mitigating it more effectively (Lazer et al., 2017). Vasu et al. (2018) stressed that lessons from the CVE (Countering Violent Extremism) experience, where critical thinking skills useful in steering youth away from radicalization, can also be applied to solve fake news issues. In addition, there are existing media literacy programs that can be implemented such as the Safer Internet Day, which is promoting responsible use of digital technology, which has been organized in Singapore by the Media Literacy Council (MLC). Besides that, as suggested by Bakir and McStay (2018), policymakers and authorities also need to take immediate steps to consult with international associations representing advertising, large advertisers, ad networks, and programmatic firms, to practice healthier advertising media environment. If all these related advertising companies choose not to support and advertise in fake news channels, this might result in the failure of the channels to survive independently.

\section{Islamic Perspective on Fake News}

Connecting faith or religion with today's media technology is becoming more common especially in humanity or practical judgment towards certain issues. According to Hope 
and Jones (2014), there are several factors known to become an influence in people's perceptions of new technologies which among them also include proximity to and familiarity with the technology, attitudes, beliefs, and values. Their study involved the Christians, Muslims, and secular as participants and they found that lack of belief in an afterlife or divine intervention led the secular participants to focus on human responsibility and the need for action, bolstering the perceived necessity of a range of technologies. This shows that religion is crucial in influencing one's decision when using new technologies.

In Islam, from Anas ibn Malik, it is reported that Rasulullah (pbuh) said, 'seeking knowledge is an obligation upon every Muslim'. With today's advanced technology, seeking knowledge has become effortless as almost everything is reachable through the Internet. As it seems easy to obtain any type of information through this medium, obtaining fake information has become a challenge too. Fake news, for example, has become a serious issue, especially when it damages one's reputation or pride in front of the public. Islam is seen to promote reverence for all forms of life, including the fair treatment of non-human species. Hilal and Andi (2013) justified that Islam is the real custodian and guardian of human rights for every human being. Thus, it is also the responsibility of human beings to protect each other especially one's pride that will affect the person's life.

Fake news reflects the arrogance of a person or party in sensationalizing something to attract people's attention. As stated under the Maqasid Al-Sharia, two key principles exhorted within the Islamic traditions are the 'protection of faith' and protection of life' as the first two of live objectives of Islamic law. From Ibn Abbas, the Messenger of Allah (pbuh) said that there is no human being except that the wisdom of his mind is in the hands of an angel. When he shows humility, the angel is ordered to increase his wisdom, when he shows arrogance, the angel is ordered to decrease his wisdom. This shows that arrogance may lead to the false sense that nobody else could teach them and that the rejection of the truth will only damage their pride and ego. In addition, the objectives of the law of Maqasid Al-Sharia also consist of five broad categories: (1) establishment of justice, (2) educating the individual, (3) upholding morality in public and private, (4) preventing hardship on individuals and society; and (5) preventing oppression. These objectives clearly emphasize the importance of education, but at the same time upholding justice and protecting the harmony of an individual and society which will not happen if people continue to believe in fake news or information.

Human rights, on the other hand, has become a weapon for these irresponsible parties in spreading false stories. This happens not only in Muslim minority countries but in the Muslim majority too. Many in a position of authority often cite a note of critics on possible divergences between the Islamic tradition and the human rights discourse for a rather insidious purpose (Ibrahim El-Houdaiby, 2018). In order to claim what they were doing is right, they often use human rights to win their judgment on their actions. Moreover, human rights are also being internationally debated throughout the world.

In a case study of Zakir Naik (as reported by MT Webmaster in Malaysia Today, October 21, 2019), an Indian Muslim preacher being accused of his comments could have been aimed at creating fissure in the multiracial nation said that people must verify the information received and the context before believing in it or passing it on. This case is very similar to fabricating facts or quotes, as mentioned previously in this paper. Either it was done intentionally or unintentionally, Naik has become the victim of those who believed the falsified quotes which clearly has been edited to highlight only on specific parts of his speech that might lead to a misconception of the viewers and listeners when they saw or listen to the edited speech. Given the freedom, which is entitled to every human being in Islam, there are also limits in the freedom which will protect and safeguarding one's doing in order not to overdoing it. This has become a debate especially with those who chose human rights as the only way to guarantee humanism. The long and rich conceptual and practical legacy of universal human rights law and history are not known today to Muslim intellectuals and policymakers (Senturk, 2018). This has prevented people from understanding the proper meaning and concept of human rights from the Islamic worldview.

However, according to Azril Mohd Amin (2018), cultural relativists object to universalism and argue that human rights are culturally dependent and that no moral principles can be applied to all cultures. As stated under the Federal Constitution, Article 
3(1) provides that Islam is the religion of the federation and this is a clear fact that everybody should take into account that emphasizes the uniqueness of Malaysia. Hence, Malaysia's perspective on human rights is that they must be in line with local cultures and norms, and in line with Islam's position as the religion of the Malaysian federation (Azril Mohd Amin, 2018).

Being one of the Muslim majority countries, Malaysia has seen to take an effort in its legal form by enforcing its newly introduced Anti-Fake News Act (AFNA). Although this could refer most towards political angle, however, there is not much evidence in putting a standard to define 'fake news', especially differentiating it from political, social, or cultural context. According to AFNA, fake news includes any news, information, data, and reports which are or are wholly or partly false, whether in the form of features, visuals, or audio recordings or in any other form capable of suggesting words or ideas. Those elements will probably fall into different possibilities that might include slander, fraud, insult, dissent, false advertising, hate speech, rumors, and many others which will affect people differently which may also include non-legal approaches.

Referring to all of the elements that could fall under the definition of fake news, Islam, in its teaching also upholds 'wasatiyyah' or being moderate. This concept proposes Muslims to bring people together, and at the same time respecting their differences as it consists self-respectable, good, lovable, useful, reliable, trustworthy, and friendly Ummah to humanity, as the good predecessors used to be during their times of self-sufficiency and cultural security (Ibrahim El-Houdaiby, 2018). The concept is directly in contrast with the elements defining fake news as mentioned earlier.

As the false news will definitely give unnecessary impacts towards certain people or parties, these affected ones could either be strong enough to face, just ignored, or will fall fast or slowly due to the damage of reputation or good names. This is totally different from Islamic ethical teachings, on the other hand, which emphasizes the protection of the weak and vulnerable (Arzoo and Mehrunisha, 2018). Knowing the uncertain impacts, Islam teaches not to practice any types of practice that were overdone which might hurt others in return of the irresponsible act, especially from fake news. Which is why, according to Asma
T. Uddin (2018), in order to protect from such harm, policymakers should help to facilitate awareness of (1) Muslim involvement in the circulation of international human rights norms, and (2) viable Islamic scholarly arguments that support a robust conception of human rights.

For instance, a case study of a Danish citizen, Salah Salem Saleh Sulaiman, who was accused of sharing an inaccurate criticism of the police on social media. He, who was on short term visit to Malaysia was charged with spreading false news after posting a video on YouTube. He accused the police took 50 minutes to respond to distress calls. Obviously, the accusation has tarnished the good name of the Malaysian police for not doing their job professionally. After the case was brought to the Court, Salah was unrepresented and that he pleaded guilty. Such accusations will not only affect the police's reputation but could also bring harm to the society in which the case might affect the society's trust towards the police and the authority by giving more space for similar accusations to happen.

To conclude, fake news is most similar to lies that affect one's perception towards some things or some people or from a legal perspective, can be claimed as a type of violation. From the Islamic perspective, ranging from a full endorsement of the status quo and subordinating Islam with its Sharia, will lead into a negotiation in considering true or fake information that a person gets. Verification of the truth in a story is crucial in order to protect a person to believe in fake information. Islam also teaches that people must work hard to realize the truth of genuine self-sufficiency; to abandon any sense of insecurity, based on a real presence of authentic security (Ibrahim El-Houdaiby, 2018). By practicing a 'wasatiyyah' or moderate life in the present modern world, one could be wiser in relating their own tradition and faith in valuing or judging news they received from any channel or medium.

\section{Conclusions}

Fake news can be summarized as a form of misinformation whether it is done intentionally or unintentionally. With its long history in journalism, we can say today that fake news is much more easily produced and disseminated with the help of technology. Various manipulation may be done by 
amateurs to manipulate information in many forms. Deception and fabrication become much easier and faster to produce, increasing the possibility of more fake news produced in the future. In terms of dissemination, social media can be one of the most popular culprits for this, making information sharing free and easy, regardless of whether it is genuine or fake. In Islam, the production and dissemination of fake news suggest arrogance in one's heart. Here, a genuine act seems to damage the doer's pride and ego. It is here that the concept of wasatiyyah is pertinent to be practiced by the Muslims, so our acts are guided with moderate and sensible decisions.

\section{References}

Ahmad, S. Shahabuddin, T. Kumar, J. Okwuibe, A. Gurtov and M. Ylianttila, "Security for $5 \mathrm{G}$ and Beyond," in IEEE Communications Surveys \& Tutorials, vol. 21 , no. 4, pp. 3682-3722, Fourthquarter 2019, doi: 10.1109/COMST.2019.2916180.

Arzoo Ahmed \& Mehrunisha Suleman. (2018, Sept 5). Gender and women's rights in Islam. The Islamic Tradition and the human rights discourse. Atlantic Council. https://www.atlanticcouncil.org/ in-depth-research-reports/report/theislamic-tradition-and-the-human-rightsdiscourse/

Asma T. Uddin. (2018). Healing the rupture between 'Islamic' and 'Western' human rights. The Islamic tradition and the human rights discourse. Atlantic Council. https://www. atlanticcouncil.org/wpcontent/uploads/2018/09/3_Healing_the_ Rupture_-_Uddin_-_Islam_and_Human_ Rights_Report.pdf

Azril Mohd Amin. (2018). Human rights in the Malay world. The Islamic tradition and the human rights discourse. Atlantic Council. https://www.atlanticcouncil.org/ wp-content/uploads/2018/09/9_Human_ Rights_in_Malay_-_Amin_-_Islam_and_ Human_Rights_Report.pdf

Bakir, V., \& McStay, A. (2018). Fake news and the economy of emotions: problems, causes, solutions. Digital Journalism, 6(2), 154-175, https://doi.org/10.1080/ 21670811.2017.1345645

Bakowicz, K. (2019). Introduction to the definition and classification of the fake news. Studia Medioznawcze, 20(3), 280289.

Bhaskaran et al. (2017). Contextualizing Fake News in Post-truth Era:
Journalism Education in India. Asia Pacific Media Educator, 27 (1), 4150. https://journals.sagepub.com/doi/ abs/10.1177/1326365X17702277

Berkowitz, D., \&Schwartz, D.A. (2015). Miley, CNN and The Onion When fake news becomes realer than real. Journalism Practice, 10 (1), 1-17. https://www. tandfonline.com/doi/abs/10.1080/17512 786.2015 .1006933

Carson, A. \& Farhall. K. (2018). Understanding Collaborative Investigative Journalism in "Post-Truth" Age. Journalism Studies, 19 (13),1899-1911. https://doi.org/10.108 0/1461670X.2018.1494515

Figueira, Á. \& Oliveira, L. (2017). The current state of fake news: challenges and opportunities. Procedia Computer Science, 121, 817-825. https://doi. org/10.1016/j.procs.2017.11.106

Finneman, T, \& Thomas, R. J. (2018). A family of falsehoods: Deception, media hoaxes and fake news. Newspaper Research Journal,39 (3). 350-361. https://doi. org/10.1177/0739532918796228

Gelfert, A. (2018). Fake news: a definition. Informal Logic, 38(1), 84-117. doi: $10.22329 /$ il.v38i1.5068

Greg, S. (2018). Fake News: As the Problem or a Symptom of a Deeper Problem? https://uu.diva-portal.org/smash/get/ diva2:1181745/FULLTEXT01.pdf

Gu, L., Kropotov, V. \& Yarochkin, F. (2017). The fake news machine: How propagandists abuse the internet and manipulate the public. Retrieved January 25, 2019 from https://documents.trendmicro.com/ assets/white_papers/wp-fake-newsmachine-how-propagandists-abuse-theinternet.pdf

Gilson, L.L, \& Goldberg, C. B. (2015). Editor's comment: So, what is a conceptual paper? Group and Organization Management, 40, 127-130.

Hilal, A. W., \& Andi S. (2013). Human Rights in Islam: A Way towards Justice for Humanity. SOSIOHUMANIKA: Jurnal Pendidikan Sains Sosial dan Kemanusiaan, 6(1),112. https://www.researchgate.net/ publication/312146735_Human_Rights_ in_Islam_A_Way_towards_Justice_for_ Humanity

Humprecht, E. (2018). Where 'fake news' flourishes: a comparison across four Western democracies. Journal of Information, Communication and Society, 22 (13),1973-1988. https://www. tandfonline.com/doi/abs/10.1080/13691 18X.2018.1474241 
Ibrahim El-Houdaiby. (2018). Rights in Islamic legal works. The Islamic tradition and the human rights discourse. Atlantic Council. https://www.atlanticcouncil.org/wpcontent/uploads/2018/09/5_Rights_in_ Islamic_Legal_Works_-_El-Houdaiby_-_ Islam_and_Human_Rights_Report.pdf

Jang, S.M., Geng, T., Queenie Li, J.Y., Xia, R., Huang, C.T., Kim, H. \& Tang, J. (2018). A computational approach for examining the roots and spreading patterns of fake news: Evolution tree analysis. Computers and Human Behavior, 84, 103-113. https:// doi.org/10.1016/j.chb.2018.02.032

Jasmi, Kamarul Azmi (June 2, 2005). Mendidik Masyarakat tentang Bahaya Fitnah. http://eprints.utm.my/id/eprint/55544/

Johnson, B. G., \& Kelling, K. (2017). Placing Facebook: "Trending", "Napalm Girl", "Fake News" and journalistic boundary work. Journalism Practice, 12(7), 817-833. https://doi.org/10.1080/17512786.201 7.1349546

Jorgensen, K.W., Williams, A., \& Hintz, A. (2018). Changing relationships between news organisations and audiences. Digital Journalism, 6(8), 945-950. https://doi. org/10.1080/21670811.2018.1505439

Lasorsa D. L. \& Dai. J. (2001). Newsroom's Normal Accident? An Exploratory Study of 10 Cases of Journalistic Deception. Journalism Practice,1(2), 159-174. https:// doi.org/10.1080/17512780701275473

Lazer, D. M., Baum, M. A., Benkler, Y., Berinsky, A. J., Greenhill, K. M., Menczer, F. (2018). The science of fake news. Science, 359(6380), 1094-1096. https://science. sciencemag.org/content/359/6380/1094

Lazer, D., Baum, M., Grinberg, N., Friedland, L., Joseph, K., Hobbs, W. \& Mattsson, C. (May 2, 2017). Combating fake news: An agenda for research and action. https:// shorensteincenter.org/combating-fakenews-agenda-for-research/

Hope, L. B., \& Jones, C. R. (2014). The impact of religious faith on attitudes to environmental Issues and carbon capture and storage (CCS) technologies: a mixed methods study. Technology in Society, 38, 48-59. https://doi.org/10.1016/j. techsoc.2014.02.003

Martens, B., Aguiar, L., Ggmez, E. \& Mueller-Langer, F. (2018). The Digital Transformation of News Media and the Rise of Disinformation and Fake News. The European Commission's science and knowledge service https://ec.europa. eu/jrc/en/publication/eur-scientificand-technical-research-reports/digital- transformation-news-media-and-risedisinformation-and-fake-news

Marchi, R. (2012). With Facebook, Blogs, and Fake News, Teens Reject Journalistic "Objectivity." Journal of Communication Inquiry, 36(3), 246-262. doi: $10.1177 / 0196859912458700$

Mohale, P., \& Leung, W. S. (2019). Fake news detection using ensemble machine learning. Reading: Academic Conferences International Limited. https://search. proquest.com/docview/2261026696?acc ountid $=33993$

Nagi, Kuldeep, New Social Media and Impact of Fake News on Society (June 6, 2018). ICSSM Proceedings, July 2018, Chaing Mai, Thailand, pp. 77-96. https://ssrn. com/abstract $=3258350$

Newman, N., Fletcher. R., Kalogeropoulos, A., Levy, D.A.L, \& Nielsen, R. K. (2017).

Reuters Institute Digital News Report 2017. https://reutersinstitute.politics.ox.ac.uk/ sites/default/files/Digital\%20News\%20 Report\%202017\%20web_0.pdf

Posetti, J., \& Matthews, A. (July 23, 2018). A short guide to the history of 'fake news' and disinformation: A learning module for journalists and journalism educators. International Center for Journalists. https://www.icfj. org/sites/ default/files/2018-S.

Senturk, R. (2018). Adamiyyah (humanity) and 'Ismah (inviolability): humanity as the ground for universal human rights in Islamic law. The Islamic tradition and the human rights discourse. Atlantic Council. https://www.atlanticcouncil.org/wpcontent/uploads/2018/09/6_Adamiyyah_ and_Ismah_-_Senturk_-_Islam_and_ Human_Rights_Report.pdf

Shu, K., Sliva, A., Wang, S., Tang, J. \& Liu, H. (2017, September 3). Fake news detection on social media: A data mining perspective. ACM SIGKDD Explorations Newsletter. https://arxiv.org/abs/1708.01967

Snyder, H. (2019). Literature review as a research methodology: An overview and guidelines.

Journal of Business Research, 104, 333339. doi: https://doi.org/10.1016/j. jbusres.2019.07.039

Tambini, D. (2017). Fake News: Public Policy Responses. Media Policy Brief 20. London:

Media Policy Project, London School of Economics and Political Science.

Tandoc, E.C., Lim, Z.W., \& Ling. R. (2018). Defining "Fake News". A Typology of Scholarly

Definitions. Digital Journalism, 6 (2), 137- 
153. https://doi.org/10.1080/21670811 .2017 .1360143

Quandt, T., Frischlich, L., Boberg, S., \& Schatto Eckrodt, T. (2019). Fake News. The International Encyclopedia of Journalism Studies, 1-6. doi: $10.1002 / 9781118841570$. iejs0128

Turk, Z. (2018). Technology as enabler of fake news and a potential tool to combat it. Brussels: European Union. https: //www.europarl.europa.eu/ RegData/etudes/IDAN/2018/619008/ IPOL_IDA(2018)619008_EN.pdf

Vasu, N., Ang, B., Teo, T.A., Jayakumar, S., Raizal, M. \& Ahuja, J. (2018). Fake news: National security in the post-truth era. https://www.rsis.edu.sg/wp-content/ uploads/2018/01/PR180313_Fake-News_ WEB.pdf
Wan Hakimin Wan Mohd, Nor Fatin Nazmin Mansor \& Nik Mohd Nabil B Ibrahim@Nik

Hanafi. (2018). Kepentingan Tabayyun Dalam Mendepani Arus Globalisasi. 4th International Conference on Islamiyyat Studies 2018. Tenera Hotel. 18th - 19th September 2018. Bandar Baru Bangi. Selangor. International Islamic University College Selangor, Malaysia.

MT Webmaster. (2009, August). Zakir Naik replies to fake news on what he allegedly said'. Malaysia Today.

Zubiaga, A., Liakata, M., Procter, R., Hoi, G. W. S., \& Tolmie, P. (2016). Analysing How People Orient to and Spread Rumours in Social Media by Looking at Conversational Threads. Plos One, 11(3). doi: 10.1371/ journal.pone.0150989 